\title{
Juez discrecional y garantismo: Facultades de disposición del litigio en el Código General del Proceso
}

\section{Discretionary judge and guarantee: Faculties of disposition of the litigation in the General Code of the Process}

\author{
DOI: $\quad$ https://doi.org/10.17981/juridcuc.15.1.2019.09
}

Fecha de Recepción: 19/06/2019 Fecha de Aceptación: 05/09/2019

\author{
Yezid Carrillo de la Rosa \\ Universitaria del Cartagena (Colombia) \\ yezidcarrillo@hotmail.com
}

\section{Abraham Zamir Bechara Llanos \\ Corporación Universitaria del Caribe, CECAR (Colombia) abraham.becharall@cecar.edu.co}

Para citar este artículo:

Carrillo, Y. y Bechara, A. (2019). Juez discrecional y garantismo: Facultades de disposición del litigio en el código general del proceso. JURÍDICAS CUC, 15(1). 229-262. DOI: http://dx.doi. org/10.17981/juridcuc.15.1.2019.09

Resumen

A tráves de la aproximación a la figura de la oralidad, vista desde el desarrollo de la actividad de administrar la justicia, en cabeza de la figura del juez, se estudian los principios de concentración e inmediación, como escenario jurídico para la conservación del derecho de defensa de las partes en un sistema de prelación adversarial. Como propuesta argumentativa, se estableceran las incidencias del juez oral y su rol como tercero, ajeno a la controversia, en la pretensión de corrección de balanceo o equilibrio en los intereses de las partes, las cuales acuden al aparato jurisdiccional del Estado como reclamación; no solo en sentido formal, sino también como una noción de justicia material desde la discrecionalidad judicial ante la vista oral del juez civil. Para ello se establecieron conexiones teóricas con herramientas conceptuales de la filosofía del derecho, aprehendidas necesariamente por la justicia procesal civil.

Palabras clave: Oralidad; juez; principios; constitucionalismo; derecho de defensa.

\section{Abstract}

Through an approach to the oral figure, seen from the development of the activity of administering justice, headed by the figure of the judge, the principles of concentration and immediacy are studied as a legal scenario for the preservation of the right of defense of the parties in a system of adversarial preemption. As an argumentative proposal, the incidences of the oral judge and his role as a third party, alien to the controversy, will be established in the attempt to correct the balance or equilibrium in the interests of the parties, who turn to the jurisdictional apparatus of the State as a claim; not only in a formal sense, but also as a notion of material justice from the judicial discretion before the oral hearing of the civil judge. To this end, theoretical connections were established with conceptual tools of the philosophy of law, necessarily apprehended by civil procedural justice. Keywords: Orality; judge; principles; constitutionalism; right of defense. 


\section{INTRODUCCIÓN}

La oralidad en la justicia civil colombiana evidenció la necesidad de su implementación como segundo momento, en la historia reciente de la cultura jurídica colombiana, luego de los inicios de la oralidad proveniente del sistema penal acusatorio. En dicho sentido, si bien, la oralidad no ha alcanzado un ciento por ciento de satisfacción en lo que de una u otra manera se ven interesados por este sistema (Burbano, 2013; Mercado, Pérez e Ibañez, 2016; Ricaurte, 2011; Canosa, 2008), el sistema penal acusatorio desde su implementación, propendió por el cumplimiento de las garantías constitucionales (Ferrajoli, 2006), y el respeto a los derechos fundamentales de los indiciados, buscando la preservación de los derechos de las víctimas. Con esta distinción básica del derecho penal, la justicia civil en aras del cumplimiento de los principios procesales como son: el principio dispositivo, el principio de concentración, el principio de inmediación, el principio de celeridad, el principio de publicidad, el principio de lealtad y buena fe, se ven en la necesaria reinterpretación de los mismos, desde el principio de la oralidad.

En este entendido, <<el sistema adversarial responde a la aplicación del principio de razonabilidad concretamente en el desarrollo de la valoración del juez >> (Bastidas, 2010). Además, relaciona la posición del juez en la oralidad de los procesos civiles:

Debe rescatarse la importante figura del juzgador, perdida o desaparecida en el modelo escrito, pues ahora la dirección judicial del proceso es una realidad en cabeza del funcionario judicial, quien con una actitud proactiva debe velar por garantizar la verdadera igualdad entre las partes, el logro de la justicia material y la verdad real haciendo prevalecer el derecho sustancial sobre la forma" (Bastidas, 2010, p. 1089).

"En muchos sistemas constitucionales contemporáneos, el límite sustancial quizá más importante para la legislación es el llamado principio de «razonabilidad»"(Guastiní, 2000, p. 247). En 
la apreciación del derecho de defensa y contradicción de las partes, los principios procesales, el de inmediación y concentración le permiten al juez equilibrar las cargas a la hora de establecer la verdad procesal.

En aras de establecer la necesidad de un procedimiento civil oral, y de determinar la importancia del rol del juez en la conducción y destinación del proceso, es necesario articular los principios fundantes del proceso oral antes mencionados, concretamente el de concentración e inmediación. En palabras de Dworkin (2012) a la institución jurídico-procesal-civil, <<nuestra pretensión no es simplemente abordar un solo proceso o el proceso, cuando hablamos de los procesos civiles, o el proceso civil es una mirada de conjunto o de integridad $>>$.

Bajo esta línea argumentativa la discrecionalidad judicial es un tópico del derecho bastante discutido, y sobre el cual se han presentados sendos debates, sobre todo la mayoría de ellos surgidos en la teoria del derecho y en la filosofía jurídica, pensar en la critica que al respecto establecería Dworkin a Hart sobre su regla de reconocimiento como regla ultima que validara todo el ordenamiento juridico.

Se propone mirar las facultades del juez que presenta el CGP (Código General del Proceso, 2012) a la luz de la discrecionalidad en la disposición de los derechos en litigio, y si realmente son facultades ejercitadas en virtud de su discrecionalidad o se amparan en criterios de valoración de la "decisión judicial" (Bechara, 2017a, p. 17; 2017b, p. 10; Bechara y Molinares, 2017, p. 165), respondiendo así, a la discrecional el juez en sus facultades y en la disposición de los derechos en litigio en la conservación del derecho de defensa de las partes.

\section{Discrecionalidad judicial:}

De la filosofía del derecho a la filosofía del derecho procesal

El tema de la discrecionalidad judicial (Guastiní, 1999; Bayón, 2010; García, 2006; Restrepo, 2011), como tópico propio de la 
teoría del derecho o de la filosofía jurídica ha sido uno de los frentes teóricos más discutidos en las últimas décadas de la cultura jurídica a nivel mundial, no solo en las familias jurídicas que provienen de un sistema de derecho del common law o de tradición anglosajón, sino además, de la familia del derecho del civil law o romano-germánico que han recorrido el pensamiento jurídico contemporáneo. Bajo esta perspectiva hablar de una discrecionalidad o no del juez en el ejercicio de sus facultades de disposición del litigio de conformidad con el CGP, es abrir el debate de un plano estrictamente teórico a una dimensión de un derecho procedimental de corte adjetivo, en sí; la discrecionalidad judicial se orienta a una mirada del derecho que se aparta del formalismo jurídico (Arrieta, 2003; Barcellona, 1989) como uso mecánico de la función judicial, en este sentido Kennedy (1973) critica el uso de la discrecionalidad judicial por configurarse en una respuesta peligrosa para la actividad judicial del derecho:

(...) Otra respuesta es la aseveración de que la legislatura debería decretar que los jueces actúen formalmente. Dado el punto de vista de la "maximización social", el argumento debe ser que todos estarían mejor si la legislatura así instruye al juez. Esto a su vez se basa en la afirmación de que en el largo plazo, cualquier discrecionalidad judicial es más peligrosa que la aplicación mecánica (1973, p. 388).

Sobre la posición que debe adoptar el juez ${ }^{1}$ como garante de los derechos fundamentales de aquellos que acuden al litigio. $<<$ Se encuentran enfrentados principios constitucionales que

1 La postura totalmente discrecional o no que debe soportar el juez mediante la conducción del proceso, está directamente relacionada con la disposición de los derechos en litigio. Al respecto se ha indicado que el juez en su rol de garantía procesal o técnicas de garantías adjetivas, no puede ser un convidado de piedra, o un mero espectador del litigio del debate procesal que por su naturaleza al ser contencioso en gran parte de los procesos, siempre va a estar determinado por la injerencia de los intervinientes, participes o partes del proceso. 
desarrollan derechos fundamentales en el marco general del derecho de acción, y es precisamente el derecho de acceso a la administración de justicia >> (Bechara, 2016, p. 64; 2011a, p. 30), como derecho fundamental por excelencia que presenta rasgos importantes para el cumplimiento de los postulados fundantes, de un Estado social de derecho, llamado también constitucional y democrático de derecho. Repensándose así, las instituciones procesales como la de administración de justicia, con la nueva axiología de la Carta de 1991, como lo manifiestan Maldonado y Montaña (2017):

La concepción de muchas instituciones del Estado, entre ellas las jurídicas, que también tuvieron que adaptarse a los lineamientos previstos por la Carta Política de 1991. Tales modificaciones, en lo que a la justicia se refiere, estaban orientadas a hacerla más dinámica y eficiente, y que pudiera, como tal, ofrecer seguridad jurídica a todos sus usuarios (p. 127).

El CGP (2012) mediante sus postulados fundantes pretende, establecer un rol de garantías por parte del funcionario judicial correspondiente, en la medida en que no se vean afectados los derechos fundamentales de los que acuden al proceso, y los resultados de los interés contrapuestos, tengan rasgos de cumplir no solo con el principio de legalidad fundante de la noción de Estado de derecho de tradición decimonónico, sino de una observancia real del principio de justicia y de razonabilidad en la decisión judicial, siendo precisamente en este aspecto que se debe buscar la verdad procesal, que tanto se habla en los procesos judiciales (Parra, 2012), a luz de un sistema de garantías de los derechos fundamentales. Configurándose la administración de justicia como una potestad ampliada más alla de las facultades del juez. $<<$ El concepto de administración de justicia no queda supeditado a la intervención de los jueces de la República como agentes del Estado >> (Meza, Arrieta y Noli, 2018, p. 192). Parra (2012) indica en la efectiva igualdad de las partes dentro del proceso: 
Esto ubica el Código General del Proceso como fenómeno social, es decir, ya no se trata de la "divina igualdad" abstracta y capturada por la razón, con el argumento de evitar las impresiones personales, sino todo lo contrario, de tener en cuenta la realidad de las partes, lo cual se logra con el interrogatorio exhaustivo de aquellas sobre el objeto del proceso y poder distribuir por ejemplo la carga de la prueba (pp. 19-20).

Parra (2012) indica con mayor detenimiento la transformación del proceso a la luz del Estado social de derecho, un proceso como vitrina social de sus mismas instituciones en este caso, siendo la judicatura que representa un derecho de acceso efectivo a la administración de justicia, presentando además la crítica prospectiva del juez ya no como espectador apartado de la realidad y de la llamada verdad verdadera debiendo interactuar en mayor medida con las partes para el esclarecimiento de los hechos y de la valoración racional, critica también establecida por Taruffo (2003) utilizada por el juez a la hora de fundamentar su decisión.

Es claro a este punto, que $<<$ el juez deberá hacer un uso razonable de su discrecionalidad juridicial aquella que el mismo curso natural del proceso le permite desarrollar y poner en marcha con todas las herramientas juridiciales, del tipo probatorio o procedimental $>>$. Uno de los principales principios generales del proceso en los que se apoya la discrecionalidad del juez, es el principio de inmediación con las partes, esta directriz indica que el juez deberá hacer uso de una inmediación efectiva y real de el con las partes, para encontrar la verdad verdadera o verdad real, con el objetivo principal de presentarle rasgos de justicia material a su fallo, la inmediación y la discrecionalidad del juez se encuentran aún más estrictamente relacionadas, no solo en el CGP (2012) sino, además en el <<modelo de adjudicación y de razonamiento en el Estado constitucional democrático, sobre todo si el juez además de aplicar normas rígidas como las reglas, aquellas que pueden estar en un código del tipo más 
sustantivo que procedimental $>>$, debe aplicar principios no solo de la Constitución, aplicando además principios rectores $\mathrm{u}$ orientadores del proceso como el de inmediación:

El juez que tiene la obligación de aplicar el derecho, considerando que este implica no solo normas sino también políticas y principios, tiene una discrecionalidad considerablemente menor que la que podría decirse que tienen si el derecho que tuviera que aplicar consistiera únicamente en normas (Kronman, 2007, p. 97).

Si bien este principio es totalmente apuntado a una adecuación procesal de las partes con el litigio los derechos en conflicto y el juez (Parra, 2012), conductor y líder del proceso, no desconoce un cumplimiento efectivo de los derechos fundamentales de garantías procesales, como son: <<el debido proceso, el derecho de defensa, juez natural y de más principios complementarios de la actuación judicial $>>$. En este entendido el juez se convierte en garante en uso proporcional de su direccionalidad en conductor de la realidad social enmarcada en proceso jurídica, ilustra este cometido la siguiente construcción:

El juez es un líder social dentro de lo que se llama la humanización del proceso, y no puede perder ese liderazgo que es esencial para las verdaderas democracias y el cumplimiento de los términos lo aprestigia así como el incumplimiento lo desprestigia, pero siempre teniendo en cuenta la calidad de sus providencias (Parra, 2012, pp. 21-22).

El análisis de la designación de práctica de pruebas en el proceso de manera oficiosa

El proceso como veníamos indicando se direcciona como una institución que preserva los intereses sociales de la comunidad, un entorno vital de preponderancia para el reconocimiento de las garantías fundamentales y derechos constitucionales de 
todos los asociados, bajo esta perspectiva el análisis de la designación de práctica de pruebas en el proceso de manera oficiosa, busca principalmente adentrarnos en la mayor medida posible, hacia un escenario en que la discrecionalidad del juez no orbite de manera desmedida o desmesurada, ante el cumplimiento y observancia del principio de legalidad. La prueba en este sentido, desde el garantismo del fallador como reducción a la actividad discrecional del operador juridico, toma un papel preponderante en los sistemas jurídicos constitucionalizados como el nuestro. Generándose inclusive la prueba como un genuino derecho fundamental. Esto lo ha advertido Luna (2018) recientemente:

A pesar de que en nuestra Carta Política de 1991 no está consagrado de manera expresa un derecho fundamental a la prueba, jurisprudencial y doctrinariamente sí se han levantado voces al respecto haciendo una interpretación extensiva de otros derechos fundamentales en donde se encuentra claramente un derecho fundamental a la prueba (p. 120).

Normativamente el CGP busca en la parte de la práctica de pruebas de oficio, que dicha observancia de la legalidad preserve los principios superiores que integran nuestro orden jurídico nacional, es así, que el código establece el mantenimiento oficioso de práctica de pruebas, regulando la materia en los artículos 169 y 170 del CGP (2012), presentando un ingrediente procedimental del mantenimiento del orden constitucional y legal, al indicar que las practica de pruebas de oficio, se regirán por la intermediación del principio de contradicción de la prueba viendo como el mismo CGP, evita excesos desmedidos en la aplicación de una discrecionalidad judicial en cabeza del operador judicial, pareciese que otorgara un sentido expreso en las llamadas técnicas de garantía procedimentales, en las que se señalan aspectos de contenido adjetivo, para orientar el cumplimiento de los derechos de estirpe sustancial que entran a 
determinarse en la disposición del litigio, o conflicto judicial, es así, que bajo este aspectos <<el CGP logra integrar un modelo de justicia garantista a su codificación estrictamente procedimental en aras de la preservación de los derechos constitucionales fundamentales $>>$.

En esta vía, el sentido integrador que demuestra el CGP, garantiza la unificación no solo de los postulados de legalidad y debido proceso constitucional, como principio sino, además que articula uno de los propósitos y acometidas primarias de la Constitución de 1991 en aras de desarrollar la administración de justicia al servicio de los ciudadanos, este entendido Canosa (2012) advierte:

En el capítulo de pruebas del Código General del Proceso resplandecen las características y propósitos del nuevo ordenamiento: la armonización del sistema procesal y probatorio con la Carta Política de 1991 y con la Ley Estatutaria de la Administración de Justicia; la integración, sistematización y unificación de las normas hoy desarticuladas y dispersas por las numerosas reformas parciales hechas al Código de Procedimiento Civil de 1970; la desformalizacion y la concentración de la actuación procesal, complicada innecesariamente y dilatada en exceso por la recargada preponderancia de la enojosa escritura; la modernización, innovación y unificación de las instituciones mediante el tránsito a la oralidad, todo con el plausible propósito de facilitar el acceso, patrocinar la oportunidad, propender por la averiguación de la verdad, disminuir las naturales diferencias entre las partes y fortalecer la inmediación y la transparencia (p. 35).

Otro de los aspectos concernientes al tema probatorio es la incidencia de la carga dinámica con la prueba de oficio, sobre esto el CGP prevé que las partes dentro del proceso deberán probar el supuesto de hecho, que conduce a las normas jurídicas s aplicables al caso concreto, lo que quiere decir que al juez las partes llevaran el conocimiento suficiente que le permita 
al operador jurídico formarse su convencimiento para la determinación de los hechos objetos de discusión. Además introduciendo elementos nuevos en la formación de los medios de prueba, como lo es $<<$ la carga dinámica de la prueba $>>$, que esta puede variar dependiendo a la oportunidad y cercanía que tenga la parte dentro del proceso con el medio probatorio de la referencia, esto se advierte, el segundo inciso del artículo 167 del Código General del Proceso (2012):

No obstante, según las particularidades del caso, el juez podrá, de oficio o a petición de parte, distribuir la carga al decretar las pruebas, durante su práctica o en cualquier momento del proceso antes de fallar, exigiendo probar determinado hecho a la parte que se encuentre en una situación más favorable para aportar las evidencias o esclarecer los hechos controvertidos.

\section{Los métodos de valoración de la prueba y la decisión judicial a partir de la discrecionalidad del operador jurídico}

Frente a los métodos de valoración de la prueba cabe determinar que el CGP establece la aplicación del principio de razonabilidad, conducente a una valoración más acertada y concordada con las normas superiores del ordenamiento jurídico. En esta medida sobre aquellas facultades del juez amparadas en una legalidad o a contrario sensu en la discrecionalidad del togado frente a las partes intervinientes en el proceso judicial en lo relativo al derecho de acción y su postulación a través de la demanda, debiendo existir una iniciativa de parte para la concreción del litigio sino existe tal iniciativa en la demanda no se determina el proceso en sí, la actuación judicial no se manifiesta sin iniciativa de parte, la cual se ejercita a través del derecho de acción materializado por medio de la demanda. 
Siendo abstracto el derecho de acción la solicitud concreta emerge en la demanda donde se encuentra la pretensión. El inciso primero del artículo 8 del CGP (2012) recoge lo prescrito en el inciso primero del artículo 2 del CPC (Constitución Polítca de Colomiba, 1991), en el sentido de si no hay demanda no existe proceso, como consecuencia de la demanda se identifican otras instituciones propias del sistema dispositivo que limitan al juez, puesto que éste se concreta a examinar y decidir lo que el accionante pretende de acuerdo con los hechos y las pruebas, que de manera separada se tratan a continuación (Forero, 2012, p. 222). El juez en dicho sentido, no solo se establece conforme a las pretensiones que lo adecuan a la decisión, sino que además en cumplimiento del principio de razonabilidad tal valoración debe buscar el sentido de justicia.

En las facultades del juez en materia estrictamente de prueba, se direccionan los acometidos en el cumplimiento de los principios constitucionales, siendo una de las manifestaciones de un esquema dispositivo la investigación de los hechos en el que las partes hayan manifestado en los actos introductorios, sea en la demanda o en las excepciones de mérito.

Los hechos en que se basan las pretensiones o en que se sustentan las excepciones de mérito, son los que deberán ser investigados sin que la decisión se funde en hechos diferentes a aquellos, debido que al contrariar lo anterior es violar el principio de congruencia como lo indica el inciso primero del artículo 305 del CPC, que reitera el inciso primero del artículo 281 del CGP. Lo anterior está relacionado con el derecho de defensa, pues las partes al conocer los hechos que su adversario aduce podrán controvertirlos, sin que el juez los sorprenda en la sentencia con hechos que jamás fueron aducidos (Forero, 2012, p. 224).

Las partes en lo atinente a las pruebas de oficio, deberán demostrar que el medio probatorio con el que se pretende allegar el poder de convicción al juez dentro del litigio no se 
posee y el dinamismo en la carga de la prueba se invierte, y es $<<$ donde entra la discrecionalidad del juez al determinar cuál parte, sin que este pierda su objetividad en el hecho de la discrecionalidad judicial de quien valora la prueba no significa que esta exceda los márgenes de acción, para administrar justicia con imparcialidad $>>$. Y así determinar quién tiene la carga de probar el hecho. "Sin embargo, este es el aspecto más incierto y peligroso de la valoración de la prueba, del cual el propio juez debe desconfiar asumiendo actitud de distancia critica, más que de dejarse envolver emocionalmente por él" (Taruffo, 2003, p. 82). Tiene una mejor posición en cuanto a ella y así, poder valorar el juez a cuál de las partes se le facilita más aportar el medio probatorio que construye la evidencia sumaria para el juez.

El sistema de oralidad en el procedimiento civil

El sistema de la oralidad en el procedimiento civil se erige como una verdadera institución jurídica, propia de la adopción de un sistema de justicia adversarial en nuestro sistema jurídico colombiano. Sobre este postulado se sienta la base de considerar realmente el sistema de oralidad, en la jurisdicción ordinaria de Colombia como un verdadero principio, desde el punto de vista de la teoría jurídica o del derecho, como fundante de toda la categoría sistémica del derecho procesal civil colombiano.

Desde el punto de vista estrictamente procesal, la oralidad como principio puede verse orientada a los diversos sistemas procesales (Rico, 2013), o a la forma de celeridad de las mismas actuaciones surtidas en los mismos procesos, entendiéndolo como una postura contraria a un sistema escritural, donde el mayor contacto con el juez de este con las partes, como un operador jurídico imparcial y dinámico posibilitarían el acercamiento neutral para así, formarse los elementos valo- 
rativos y de juicio de manera uniforme, critica y ponderada. Sobre esta visión se presenta una crítica puntual de Rico (2013), al decir:

No obstante, a pesar de las bondades que en materia de descongestión pueda representar el primero (sistema oral), se objeta la inseguridad del respaldo de la actuación, sino se cuenta con las actualizaciones tecnológicas y las adecuaciones locativas que este tipo de actuaciones demandan (Rico, 2013, p. 443).

Esta posición lo que pretende demostrar es que al implementarse en un orden jurídico concreto, un sistema de justicia oral adversarial se superaría además con gran ventaja, para la prevalencia del principio de la prevalencia del derecho sustancial de las partes por los de un sistema con exceso formalismo, donde una exigencia hipertecnicista de formalidades jurídicas del tipo escritural, desconocen la puesta en marcha del acceso, no solo efectivo sino eficaz del derecho a acudir a la administración de justicia para la superación de las controversias de los ciudadanos. Al respecto, otra posición es la defendida por Azula (2006):

Tampoco es oral el regulado por la norma como tal, pero que, por la imposibilidad de surtirlo en esa forma, en razón de la ausencia de elementos necesarios, adopta en la práctica el escrito, como acontecía con el procedimiento laboral que rige en nuestro medio. El verdadero proceso oral es aquel en el cual toda la actuación se surte en esa forma, mediante audiencia, como acontece en el regido por el sistema de la ley común. Además, que es el ideal, por permitir la aplicación de muchos de los restantes principios, como son los de la concentración, economía, inmediación, etc” (p. 84).

En este sentido el CGP propende por el desarrollo de oralidad como principio fundante de la actividad jurisdiccional, que despliega la justicia procesal civil colombiana. Busca 
hacer la superación de los sistemas estrictamente ceñidos a lo escritural, donde el contacto con el juez, quedaba reglado a la interacción con los mismos funcionarios del juzgado, como la vista del secretario, los escribientes, sustanciadores, entre otros empleados de los despachos judiciales. Puntualmente este querer no solo de la implementación de la oralidad sino, su puesta en marcha eficaz es concretado por el CGP (2012):

6. Prohibiciones. ${ }^{2}$ Las intervenciones orales no podrán ser sustituidas por escritos.

El acta se limitará a consignar el nombre de las personas que intervinieron como partes, apoderados, testigos y auxiliares de la justicia, la relación de los documentos que se hayan presentado y, en su caso, la parte resolutiva de la sentencia.

Solo cuando se trate de audiencias o diligencias que deban practicarse por fuera del despacho judicial o cuando se presenten fallas en los medios de grabación, el juez podrá ordenar que las diligencias consten en actas que sustituyan el sistema de registro a que se refiere el numeral 4 anterior o que la complementen.

El acta será firmada por el juez y de ella hará parte el formato de control de asistencia de quienes intervinieron. Cualquier interesado podrá solicitar una copia de las grabaciones o del acta, proporcionando los medios necesarios para ello.

En ningún caso el juzgado hará la reproducción escrita de las grabaciones.

De las grabaciones se dejará duplicado que hará parte del archivo del juzgado, bajo custodia directa del secretario, hasta la terminación del proceso (art. 107).

${ }^{2}$ Negrillas del autor. 
El rol del juez en la oralidad de los procesos civiles: Conducción y guía del proceso

La oralidad en el procedimiento civil toca directamente con el artículo 229 de la Constitución (1991), el cual consagra de manera positiva el derecho fundamental de acceso a la administración de justicia. El rol del juez en la oralidad precisamente busca, en un primer orden la descongestión de los despachos judiciales. Su función va a estar orientada por sistema de corte adversarial, donde la importancia de su actividad jurisdiccional va estar enmarcada en el equilibrio o una verdadera proporcionalidad, de las partes que intervienen en un litigio y cuyas pretensiones oponen un conflicto de intereses.

Concretamente, el CGP (2012, art. 3), destaca un procedimiento oral y por audiencias: "las actuaciones se cumplirán en forma oral, publica y en audiencias, salvo las que expresamente se autorice realizar por escrito o estén amparadas por reserva". Donde se reconoce, que la función del juez, es vital para el verdadero desarrollo del derecho en términos de justicia y eficacia. $\mathrm{Al}$ respecto se estructura la defensa de la oralidad como verdadera norma de principio a través de la labor jurisprudencial de la Corte Constitucional:

Concebida a la manera de principio, la oralidad se proyecta entonces como una norma cuyo alcance puntual debe ser definido por el legislador de acuerdo con las características y necesidades de cada procedimiento en particular, lo que permite que su desarrollo e implementación pueda hacerse en forma gradual (Sentencia C-713, 2008).

La defensa de un sistema de oralidad en la jurisdicción ordinaria, y puntualmente en los marcos competenciales del procedimiento civil, resultaría del establecimiento del mismo como un ideal del cumplimiento de los postulados del Estado constitucional de Derecho entre ellos el valor fundamental de la paz. Enten- 
diendo de una forma conexa que el principio de oralidad (López, 2007) aplicada a una administración de justicia, desarrolla y construye escenarios de paz social y porque no de "paz jurídica". Desde el punto de vista de la ideal formación de la oralidad en nuestra justicia procesal civil, es respaldada por López (2007):

(...) El sistema oral es ideal, el mejor, pero únicamente podría funcionar con éxito en actuaciones de única instancia y donde el juez decida verdad sabida y buena fe guardada; o sea, solo en restringidísimos asuntos, de ahí que más que perder el tiempo e infructuosos ensayos para aplicarlos, mucho mejor estarían encaminadas las preocupaciones y esfuerzos del Estado para preparar adecuadamente al personal subalterno de la rama jurisdiccional de las técnicas y herramientas tecnológicas que permitirán agilizar la evacuación de las audiencias y diligencias (pp. 122-123).

En este orden de ideas, el juez desde la vista oral se erige como conductor y guía del proceso, en cuanto puede practicar pruebas de oficio en virtud del establecimiento de los medio de prueba, y elementos fundantes de su convicción en la valoración de los argumentos o razones en contra frente a la disputa de los derechos en litigio. Es así, como el juez forma su entendido del derecho frente a la verdad procesal, verdad construida desde la puesta en marcha no solo de las facultades oficiosas del juez sino de las mismas discrecionales de la actividad jurisdiccional. Por estas razones el juez se convierte desde la oralidad en un verdadero garante de los derechos fundamentales de los intervinientes en un proceso judicial:

Los jueces somos elementos de cohesión social y de pasificación. Por eso somos responsables en este nuevo "Estado social de derecho" de vigilar en las causas que conocemos el estricto cumplimiento de la Constitución y la ley, pues de alguna manera somos custodios y depositarios de la soberanía popular expresada en las normas constitucionales y legales, disposiciones a las cuales debe imprimírseles un eficaz y útil sentido en pro del anhelado bienestar social (Vargas, 2007, p. 368). 
Los principios fundantes del proceso oral y el papel del juez en la incidencia de las actuaciones judiciales

Este aparte, se centra en el desarrollo de los principios de concentración e inmediación en la conservación del derecho de defensa de los intervinientes en el proceso civil: relación de los principios fundantes del proceso oral y papel del juez en la incidencia de las actuaciones judiciales frente a las partes en el litigio judicial.

En primer orden el principio de concentración, busca que las actuaciones surtidas a la interior del proceso se desenvuelvan de manera tal que la conducción de la vista judicial sea ágil, dinámica, sin interrupciones sin dilaciones o demás demoras que puedan afectar la formación de la futura decisión judicial. Es decir se opone a la dispersión de los actos procesales. Buscando igualmente este principio por una tendencia al desarrollo agrupado a todas las formas de intervención judicial dentro de un proceso, en este caso en los procedimientos de carácter civil. Bajo esta línea de argumentos, el principio procesal de concentración se encuentra expresamente reglado en el CGP (2012):

El juez deberá programar las audiencias y diligencias de manera que el objeto de cada una de ellas se cumpla sin solución de continuidad. No podrá aplazar una audiencia o diligencia, ni suspenderla, salvo por las razones que expresamente autoriza este código (art. 5).

Echandía (2009) destacaría la aplicación efectiva del principio de concentración exclusivamente en los procesos bajos los sistemas o el principio de oralidad fundante de los mismos:

Es en los procedimientos orales en donde este principio tiene aplicación adecuada, ya que en la audiencia se presentan todas las excepciones y se plantean todos los incidentes, además de allegarse las pruebas y formularse los alegatos de derecho, y por regla general en la sentencia se resuelven todos estos hechos y problemas, sin que pueda suspenderse el curso del litigio para darle previa solución a uno de ellos (2009, p. 67). 
Finalmente, en cuento al principio de inmediación, este busca relacionar al juez directamente con las practica de pruebas dentro del proceso, así, como surtimiento de las audiencias y diligencias procesales tendientes al esclarecimiento de los hechos y pretensiones materias del litigio, siendo en la misma vista judicial que este principio toma una especial relación con el de oralidad, ya que como corresponde al principio de oralidad las audiencias tendientes al modelo adversarial buscan ponerle de presente al juez como conductor principal del proceso todos los elementos de juicio a la mano, para la formación y valoración de su criterio tendiente a la construcción racional de la decisión judicial. El principio de inmediación es señalado taxativamente por el Código General del Proceso (CGP, 2012):

El juez deberá practicar personalmente todas las pruebas y las demás actuaciones judiciales que le correspondan. Solo podrá comisionar para la realización de actos procesales cuando expresamente este código se lo autorice. Lo anterior, sin perjuicio de lo establecido respecto de las pruebas extraprocesales, las pruebas trasladadas y demás excepciones previstas en la ley (art. 6).

Este principio estructura toda la fundamentación de las demás normas procesales que conforman la justicia procesal civil, y destaca una relación directa del administrador de justicia con los que intervienen directamente en el proceso, buscando de manera continua y permanente el establecimiento de una clara relación procesal, tanto del director como juez del proceso y las partes interesadas en la resolución del conflicto o la controversia jurídica. Frente a esta propuesta, la Corte Constitucional (2002) defiende la siguiente posición: 
Se considera que mediante la aplicación de dicho principio (inmediación ${ }^{3}$ ) es más posible descubrir la verdad de los hechos y proferir una decisión justa, es decir, alcanzar el ideal del derecho. Su mayor expresión tiene lugar en los procesos orales (Sentencia C-830, 2002).

Axiológia procesal:

Garantísmo judicial en materia de medidas cautelares

El CGP visto desde la teoría garantista del derecho pretende establecer instituciones procesales renovadas hacia un derecho procesal más justo y mejor equilibrado. Sobre esta concepción es cardinal para la consolidación de dicho postulado es vital la observancia de dos principios, como lo son el principio de razonabilidad y el principio de proporcionalidad, juntos se interpretan como la objetivación de una razón judicial y del equilibrio en la búsqueda de una verdad procesal. En este orden nace nuestro interrogante y es precisamente el que determinara los aspectos relevantes que en relación con el CGP introduce sobre medidas cautelares, observándolo en paralelo con el CPC nuestro enfoque es fundamentalmente desde una axiología del derecho, nos apoyamos en la teoría de principios, para explicar no solo el contenido de la institución cautelar sino su fundamento y concordancia con los principios superiores del ordenamiento jurídico. ¿Cuál es el principal avance procedimental que introduce el nuevo código general del proceso en materia de medidas cautelares con relación al CPC?

Hoy el derecho se construye a través de los principios, a lo que Zagrebelsky (2007) denomina:

${ }^{3}$ Negrillas del autor. 
"El derecho por principios". Esta propuesta se acerca a una verdadera axiología del derecho, construyéndose así un escenario jurídico más cerca de los valores y principios a lo que también en apoyo de la tesis de la necesidad conceptual y necesaria entre derecho y moral (Carrillo, 2009a; 2009b) defendida por Alexy, fundamenta uno de los principales postulados del Estado constitucional de derecho.

En dicho contexto, un fenómeno de nueva data como lo es el de la constitucionalización del derecho, ha traslado toda la intensión de la ciencia jurídica hacía la materialización de los derechos y garantías que consagran las Constituciones o cuerpos de derechos, $<<$ he aquí que cobra una especial consideración la teoría garantista del derecho propuesta por Ferrajoli con la que ha querido trasladar desde un estricto sentido del derecho penal, al derecho procesal que más concretamente él ha denominado "técnicas de garantía" >>, lo cual en aplicación del derecho procesal se traduce en la consolidación efectiva de una justicia procedimental que busca la justicia material y la consolidación de los derechos constitucionales fundamentales, o garantías procesales de primer orden en palabras de Ferrajoli (2006).

Su propuesta se enfoca en determinar que los procedimientos establecidos para la consolidación de los derechos deben pretender no solo responder a garantías formales, o garantismo inocuo es decir, solo de tratar de cumplir que algunos principios como el del debido proceso no se rompan en la construcción procesal sino, en determinar que la postura esencial traducida en una garantía de primer orden responda a una verdadera proporcionalidad de las causas objeto del litigio, por lo que el juez más que valorar, debe de razonalibilizar y proporcionalizar sus providencias en su contenido amplio y general. 
La axiología de los principios le permitirá a la propuesta de un garantismo procesal, construir un razonamiento teórico con enfoque reflexivo y crítico, sobre lo que el CGP introduce en materia de medidas cautelares. Lo que traduce que la construcción del derecho procesal de hoy, se aleja ya estrictamente de una tradición de un Estado legalista decimonónico, en la conformación de un verdadero Estado constitucional, con relación a la concreción judicial de los derechos fundamentales positivizados en las Constituciones. $<<$ El Estado constitucional democrático se solidifica sobre unos pilares de libertades, siendo estas individuales y colectivas, lo que está claro es que a la hora de tutelar estas libertades con ellas mismas se van consolidando garantias fundamentales $>>$ (Carrillo y Bechara, 2018, p. 25).

Sobre este entendido <<surge una axiología jurídica o del derecho cuyo origen o introducción se da principalmente por el derecho constitucional, pero apoyado rotundamente por una filosofía del derecho y de la construcción teórica de la ciencia jurídica >> (Carrillo y Bechara, 2018, p. 48), un derecho principial con alto contenido valorativo desde las normas de principio (Bechara, 2019), como lo refiere Zagrebelsky (2007), formula que supera un derecho hegemónico de tradición legalista:

La expresión jurídica de esta hegemonía era la ley, a la que, en consecuencia, se le reconocía superioridad frente a todos los demás actos jurídicos y también frente a los documentos constitucionales de entonces. La ocasión para dar un fundamento más sólido que el proporcionado por la ley estatal surgió con la reacción que se produjo, al término de la segunda guerra mundial, en aquellos Estados que se vieron en la necesidad de refundar las instituciones constitucionales después del totalitarismo fascista y nacionalsocialista (2007, p. 65). 
Nuestra tesis defiende la relación de las medidas cautelares como medios de afirmación garantista del derecho ${ }^{4} \mathrm{y}$ de los derechos, con fuertes consideraciones procedimentales. La finalidad cardinal de las medidas cautelares es la de brindar protección a los derechos subjetivos, salvaguardando de intereses personalísimos que se encuentran en disputa y son objeto del litigio, como cumplimiento de una garantía real de efectividad y eficacia en la administración de justicia. Para García y García (2005) las medidas cautelares constituyen actos jurisdiccionales de naturaleza preventiva y provisional, que de oficio o a solicitud de parte, se ejecutan sobre personas bienes y medios de prueba para mantener respecto de estos un estado de cosas similar al que existía al momento de iniciarse el trámite judicial, buscando la efectiva ejecución de la providencia estimatoria e impidiendo que el perjuicio ocasionado por la vulneración de un derecho sustancial, se haga más gravoso como consecuencia del tiempo que tarde el proceso en llegar a su fin.

En aras de establecer un cuadro comparativo del CPC con el CGP, es menester para las finalidades de este estudio, determinar el porqué de la consolidación en su momento el CPC (art. 327) el cual establece bajo la denominación de cumplimiento y notificación de medidas cautelares; estas se cumplirán inmediatamente, antes de la notificación a la parte contraria del auto que las decrete, si fuesen previas al proceso se entenderá

\footnotetext{
${ }^{4}$ Una verdadera aplicación de una teoría garantista procedimental, busca el reposicionamiento de los derechos fundamentales constitucionales, de las partes que acuden al desarrollo de un verdadero derecho esencial como lo es el acceso a la administración de justicia, el derecho procesal más que ser un derecho formal por excelencia, debe abdicar por la reivindicación de los principios de justicia material y prevalencia del derecho sustancial que relaciona nuestra Constitución, es así que llegamos al análisis, que en cuanto a las medidas cautelares el CGP, relaciona una verdadera construcción de una axiología jurídica en respecto de los principios superiores del ordenamiento juridico colombiano.
} 
que dicha parte queda notificada el día en que se actué en ellas o se lleve a cabo la respectiva diligencia. Sobre el particular, la Corte Constitucional mediante la Sentencia C-925 (1999) estableció:

Partiendo del soporte de que el legislador, conforme con el artículo 150, numerales 1 y 2 de la Carta Política, como representante del poder soberano del pueblo, ejerce una libertad de configuración normativa sobre el diseño de los procedimientos jurisdiccionales aunque bajo los principios constitucionales y el respeto a la integridad de los derechos fundamentales que está obligado a garantizar, afirma que las normas procedimentales que el legislador expida tienen que estar cimentadas en criterios de proporcionalidad y razonabilidad, que son los que permiten la efectiva aplicación del concepto de justicia, y por contera, hace posible el amparo de los intereses en conflicto.

Principales avances procedimentales del cgp en materia de medidas cautelares con relación al CPC

Las medidas cautelares constituyen actos jurisdiccionales de naturaleza eminentemente preventiva y provisional, que de manera oficiosa o a solicitud de la parte interesada se pueden ejecutar sobre personas, bienes y medios de prueba para mantener respecto de estos un estado de cosas similar al que existía al momento de iniciarse el trámite judicial, buscando la efectiva ejecución de la providencia estimatoria e impidiendo que el perjuicio ocasionado por la afectación, o lesión de un derecho subjetivo, se haga más gravoso como consecuencia del tiempo que tarda el proceso en llegar a su fin (Calamandrei, 1996, p. 157). En este entendido $<<$ la medida cautelar se instituye como consolidación de una teoría garantista del derecho procedimental $>>$ en la búsqueda de las herramientas jurídicas tendientes a consolidar las casusas antes de la consolidación de una sentencia en sentido estricto como decisión judicial. 
Además de lo anterior existe otro fundamento que construye la noción de medidas cautelares, y es precisamente que estas tienden a mantener el equilibrio procesal y a salvaguardar la efectividad de la acción judicial, garantizando con ello los derechos de igualdad y acceso a la administración de justicia, derechos que se hacen nugatorios cuando la función jurisdiccional no se muestra eficaz y protectora (Bechara, 2015).

Como sustento constitucional, se muestra el argumento precedente en razón de que un derecho en clave garantista orientado a un procedimiento civil adversarial, debe inicialmente propender por la observancia y prevalencia de derechos fundamentales como los que mencionábamos renglones atrás, y es precisamente que desde nuestro enfoque axiológico princi-

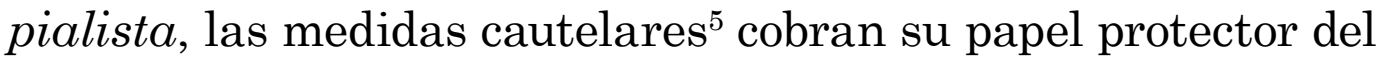
equilibrio procesal en los litigios y causas judiciales.

Con relación a esto Carnelutti (1944) indica como la medida cautelar ${ }^{6}$ es ante todo, una decisión de oficio que trata de crear un estado jurídico provisional que dure hasta que se defina el derecho en la litis, tratándose de un arreglo temporal del liti-

${ }^{5}$ La relación de las medidas cautelares como instrumentos propios para la preservación del equilibrio procesal dentro del litigio, se estructuran en apoyo de los principios constitucionales en una axiología del derecho, que más que ser una herramienta de interpretación del derecho es una herramienta de adjudicación o aplicación del derecho, con observancia y prelación de los principios de proporcionalidad y razonabilidad.

${ }^{6}$ En apoyo de la jurisprudencia de la Corte Constitucional, se ha establecido los criterios de transitoriedad y provisionalidad en el establecimiento de las medidas cautelares y así como los márgenes de acción competenciales a los límites de la libertad de configuración legislativa, mediante la Sentencia C-485 (2003), este alto tribunal indico:

"El legislador, aunque goza de una considerable libertad para regular el tipo de instrumentos cautelares y su procedimiento de adopción, debe de todos modos obrar cuidadosamente, por cuanto estas medidas, por su propia naturaleza, se imponen a una persona antes de que ella sea vencida en juicio". 
gio que solo eventualmente, pueda tornarse definitivo a partir de la decisión final. En virtud de la medida cautelar la res no es pues iudicata, sino arreglada de modo que pueda esperar la conclusión del juicio, este concepto se aclara comparándolo con el vendaje de una herida, por ese hecho tiene el carácter eminentemente provisional y transitorio.

Uno de los principales avances en materia de medidas cautelares que trae el Código General del proceso ${ }^{7}$, es que regula con precisión e individualidad las etapas o segmentos de solicitud, decreto, práctica, modificación, sustitución o revocatoria de las medidas cautelares.

A propósito de esto, el modelo propio de un proceso civil adversarial parecería que se predicara como postulado fundamental de su desarrollo, la práctica de pruebas a ruego como en la de medidas cautelares, se trata es en un sistema de adversarios en los que la igualdad procesal se viera garantizada en la primacía de la observancia de los principios de proporcionalidad y razonabilidad.

Otro de los avances importantes en el CGP frente a las cautelas es el referente, a la cautela innominada en el artículo 590 del CGP (2012), estipula la que se podría denominar cautela atípica, genérica o innominada, lo que evidencia que el nuevo código rechaza la postura del numerus clausus (Villamil, 2012) en medidas cautelares para matricularse con la singularidad de una protección hacia el númerus apertus. Cabe resaltar la mirada que plantea Villamil (2012) en cuanto al numerus apertus:

${ }^{7}$ El CGP en lo correspondiente a las pruebas de oficio y la discrecionalidad judicial del operador jurídico, establece unos rasgos grandes entorno al garantismo constitucional y al garantismo judicial que pretende establecer la administración de justicia con esta nueva normatividad procedimental y de estirpe probatoria. 
El Código General del Proceso, en materia de medidas cautelares, expresa un sesgo iuspublicista, en tanto otorga un mayor poder al juez, lo cual se expresa de varias maneras en el artículo 590. Así, cuando el artículo se refiere a la proporcionalidad, necesidad y utilidad de la medida, otorga al juez en el caso de la cautela genérica un amplio margen de discrecionalidad para decidir sobre esas medidas (2012, p. 175).

Diferencias y semejanzas que en materia de medidas cautelares establece el cgp en comparación con el cpc

Para este último aparte es necesario confrontar los dos estatutos procesales, nos referimos al CGP y su relación con el CPC, para ello iniciaremos comparando el capítulo II referente a las medidas cautelares del CGP.

El Capitulo II del CGP (2012), Medidas Cautelares, en su articulo 476 (Guarda y aposición de sellos), junto con el articulo paralelo del CPC (1991) 575 con idéntico nomen juris, la primera semejanza entre dos artículos es la indicada en el primer inciso, con relación al termino de 30 días, sobre el que se estipula el periodo luego de la muerte del causante para pedir el aseguramiento de los muebles y documentos del difunto, como primera diferencia es la que demuestra el segundo inciso del artículo, ya que aquí no se precisa en el CGP. la relación o determinación precisa de los bienes, tal como si lo mostraba el CPC igualmente en el tercer inciso de los artículos encontramos otra semejanza, y es la tendiente a la determinar la competencia preventiva del juez que debe conocer el proceso de sucesión así como el juez municipal del territorio donde se encuentran los bienes.

Finalmente en el último inciso de los artículos en análisis, se pone de presente otra semejanza, pues se practicara dentro de los dos días siguientes el decretamiento de la medida señalando fecha y hora para la diligencia. 
Articulo 477 CGP.

Prácticas de la guarda y aposición de sellos, y su paralelo del CPC, el artículo 576

Los tres primeros incisos de los artículos guardan estrecha relación y semejanza, la primera diferencia notoria en este articulado, es la que se estructura en el inciso cuarto, ya que en el CGP (2012) se ordenara depositar las joyas u objetos preciosos en un establecimiento especializado, es decir aquel establecimiento preparado para establecer la custodia y el manejo de tal objetos, mientras que en su aparte del artículo del CPC (1991) se indica que el deposito debe ser ya no en un establecimiento especializado sino en un establecimiento bancario.

Continuamos con semejanzas en el articulados en los incisos quinto, sexto y séptimo, ya que en el final en el octavo existe otra diferencia, la que muestra que si al practicarse la diligencia de oposición, para resolver sobre su admisión se remite a lo preceptuado en los numerales 1 y 2 del art. 596, mientras en el CPC se remite a lo preceptuado en el parágrafo 1 e inciso primero del parágrafo 2 del artículo 686.

Articulo 478 CGP.

Terminación de la guarda, articulo 578

terminaciones de la guarda y orden de secuestro del CPC

Estos dos artículos indican una diferencia sustancial, y es que el referente al CGP (2012) preceptúa que si dentro de los diez días siguientes a la diligencia no se hubiere promovido el proceso de sucesión, el juez levantara las anteriores medidas, salvo que se haya solicitado el secuestro de los mismos, al diferencia con su paralelo del CPC (1991) radica en que el juez declara terminadas las anteriores medidas y decretara el secuestro provisional de los bienes, que se regirán por lo dispuesto en el artículo 579. Iniciado que en el proceso, se levantaran dichas medidas y se entregaran los bienes a quienes tengan derecho a administrarlos. 
Finalmente uno de los artículos más importantes sin el que no podemos dejar de hacer el análisis comparativo, es el referente al artículo 480 (CGP, 2012) embargo y secuestro, articulo 579 (CPC, 1991) embargo y secuestro provisional.

La primera diferencia que observamos es la consagrada en el inciso cuarto, que menciona al hacer entrega el secuestre, se cerciorara de que los bienes pertenezcan al causante, conyugue o compañero permanente y con tal fin examinara los documentos que encuentre o se le presenten e interrogara a los interesados y demás personas que asistan a la diligencia, el paralelo del CPC no indica que o hace relación al conyugue o compañero permanente, sino que relaciona los bienes que le pertenezcan al causante, con el examen de los documentos que lo acrediten.

En el inciso séptimo de estos articulados, relacionamos otra diferencia, ya que el referente del CGP (2012) indica que si se demuestra que las medidas decretadas recaen sobre bienes propios del conyugue o compañero permanente, se abstendrá de practicarlas. Si ya hubiesen sido practicadas, el interesado podrá promover incidente para que se levanten. Su equivalente del CPC (1991) muestra que el conyugue sobreviviente podrá solicitar que se levante las medidas que afecten sus bienes propios y para ello se tramitara incidente. El auto que lo decida es apelable en el efecto diferido.

\section{Conclusiones}

La oralidad como principio se muestra como una norma que busca la fundamentación de una justicia más comedida, una justicia procesal civil efectiva, en respuesta a la alta congestión de los despachos judiciales, como superación de un sistema escritural donde las mayorías de las vistas judiciales eran surtidas a través de la fundamentación de sendos cuerpos letrados, que permitían la generación de una jurisdicción ordinaria, totalmente paquidérmica y anticuada. La oralidad se complemen- 
ta con otros dos principios fundantes de los sistemas procesales, los cuales son, el de concentración y el de inmediación.

Buscando generalmente en primer lugar, que los actos surtidos al interior del pleito se desplieguen de manera tal que la guía de la vista judicial sea ágil, dinámica, sin interrupciones, sin dilaciones o demás demoras que puedan afectar la columna de la futura decisión judicial. Y en segundo lugar, el principio de inmediación aboga en una justicia oral, avances en la construcción de la verdad procesal desde una interacción directa y acertada con las partes al interior de los procesos.

Es evidente que los parámetros que utiliza el CGP, conducen a una armonización de los postulaos superiores, que la misma Constitución estableció en sus inicios, ya en un marco más dinámico no solo soportando aspectos de legalidad en estricto sensu, como el debido proceso, o los principios generales del proceso, en la determinación de unos rasgos constitucionales por excelencia, posibilita así, una inclusión de los principios y valores superiores del ordenamiento, donde ahora una axiología-juridico-procesal prioriza la participación de técnicas de garantía procedimentales, que amparen los derechos fundamentales de los ciudadanos.

\section{REFERENCIAS}

Arrieta, A. (2003). Justo formalismo. La aplicación formal del derecho, casos y límites. Precedente, (-). 163-184. https://doi.org/10.18046/prec.v0.1402

Azula, J. (2006). Manual de derecho procesal. Tomo I, Teoria general del proceso. (9 Ed.). Bogotá, D.C.: Temis.

Barcellona, P. (1989). Estado de derecho, igualdad formal y poder económico (Apuntes sobre formalismo jurídico y orden económico) in Ilustración y Revolución. Anales de la Cátedra Francisco Suárez, 29(1). 45-62.

Bayón, J. (2010). Permisos, lagunas y discrecionalidad judicial: Respuesta a Bulygin. Doxa. Cuadernos de filosofía del derecho. (33). 307-320. 
Bastidas, R. (2010). La formación del juez en la oralidad. XXXI Congreso Colombiano de Derecho Procesal. Universidad Libre, Bogotá, Colombia.

Bechara, A. (2019). Jurisprudencia de principios e interpretación de los derechos fundamentales. Barranquilla: Universidad del Norte.

Bechara, A. (2017a). Jurisprudencia de principios e interpretación de la Constitución: el escenario de la Corte Constitucional colombiana. Justicia, (32). 15-37. https://doi. org/10.17081/just.23.31.2903

Bechara, A. (2017b). La carga invertida de los derechos fundamentales como procedimiento de creación judicial: diálogo jurisdiccional en la garantía de protección secundaria. La Creación judicial del derecho y el diálogo entre jueces. Universitat Autònoma de Barcelona, Bellaterra.

Bechara, A. (2016). Nuevos sujetos de especial protección constitucional: defensa desde la teoría principialista de los derechos fundamentales. Justicia, 21(29). 28-44. http:// dx.doi.org/10.17081/just.21.29.1231

Bechara, A. (2015). Análisis del precedente judicial y sentencia de unificación jurisprudencial en la ley 1437 de 2011: del precedente constitucional al precedente contencioso administrativo. Saber Ciencia y Libertad, 10(1). 61-69. https://doi.org/10.18041/2382-3240/saber.2015v10n1.869

Bechara, A. (2011a). La ponderación y los derechos fundamentes. Cartagena: Universidad Libre.

Bechara, A. y Molinares, V. (2017). Entre la interpretación y la norma: la tasa razonable de justificación constitucional. Revista de Derecho, (48). 163-188. http://dx.doi. org/10.14482/dere.48.10144

Burbano, C. V. (2013). La oralidad en la justicia civil como elemento del debido proceso: un enfoque de derechos humanos. Civilizar Ciencias Sociales y Humanas, 10(18). $15-25$. 
Canosa, U. (2008). Hacia la oralidad en la justicia civil. Temas vigentes en materia de derecho procesal y probatorio: homenaje al doctor Hernando Morales Molina. Bogotá, D.C.: Universidad del Rosario.

Canosa, U. (2012). Código general del proceso. Aspectos probatorios. XXXIII Congreso Colombiano de derecho procesal. Universidad Libre, Bogotá, Colombia.

Carrillo, Y. (2009a). Acerca de la razón práctica en el derecho y de sus límites en la justificación de las decisiones judiciales. Revista Jurídicas, 1(6). 52-68.

Carrillo, Y. (2009b). La inclusión de la moral en el derecho y la encrucijada actual del positivismo juridico. Dialogo de Saberes, (31). 213-229.

Carrillo, Y. y Bechara, A. (2018). La balanza de los derechos. Bogotá, D.C.: Ibáñez.

Calamandrei, P. (1996). Instituciones de derecho procesal civil. (Vol. I). Buenos Aires: Ediciones jurídicas Europa América.

Carnelutti, F. (1944). Sistema de derecho procesal civil. (Tomo I). Buenos Aires: Uteha.

Dworkin, R. (2012). El imperio de la justicia. (2 Ed.). Barcelona: Gedisa.

Echandía, D. (2009). Nociones generales de derecho procesal civil. (2 ed.). Bogotá, D.C.: Temis.

Ferrajoli, L. (2006). Las garantías constitucionales de los derechos fundamentales. Doxa, (29). 15-31.

Forero, J. (2012). Facultades del juez en el Código general del Proceso. XXXIII Congreso Colombiano de derecho procesal. Universidad Libre, Bogotá, Colombia.

García, E. y García, J. (2005). Medidas cautelares, Introducción a su estudio. (2 Ed.). Bogotá, D.C.: Temis.

García, J. (2006). ¿Existe discrecionalidad en la decisión judicial? Isegoría, (35). 151-172. https://doi.org/10.3989/ isegoria.2006.i35.34 
Guastiní, R. (2000). La constitución como límite a la actividad legislativa. Derechos y Libertades, 8(1). 241-252.

Guastiní, R. (1999). Principios de derecho y discrecionalidad judicial. Jueces para la democracia, (34). 39-46.

Kennedy, D. (1973). Legal formality. The Journal of Legal Studies, the University of Chicago Law School, 2(2). 351398.

Kronman, A. (2007). El problema de la discrecionalidad judicial. Academia, 5(10). 95-99.

López, H. (2007). Instituciones de derecho procesal civil colombiano. Tomo I. (9 Ed.) Bogotá, D.C.: Dupre.

Luna, F. (2018). El mito del cientificismo en la valoración de la prueba científica. Jurídicas CUC, 14(1). 119-144. http://dx.doi.org/10.17981/juridcuc.14.1.2018.6

Maldonado, M. y Montaña, L. (2017). Arbitraje: mecanismo alternativo de solución de conflictos o privatización judicial. Jurídicas CUC, 13(1). 121-146 http://dx.doi. org/10.17981/ juridcuc.13.1.2017.6

Mercado, C. Perez, S. e Ibáñez, A. (2016). Aplicación al sistema de la oralidad en los procesos civiles-solución a una expectativa de justicia pronta. Advocatus, 14(1). 112-121.

Meza, A., Arrieta, M. y Noli S. (2018). Análisis de la conciliación extrajudicial civil en la Costa Atlántica colombiana. Jurídicas CUC, 14(1). 187-210. http://dx.doi. org/10.17981/juridcuc.14.1.2018.9

Parra, J. (2012). Reflexiones sobre algunos aspectos importantes del Código general del proceso. XXXIII Congreso Colombiano de derecho procesal. Universidad Libre. Bogotá, Colombia.

República de Colombia. Asamblea Constituyente (1991). Constitución Política de Colombia. Gaceta Constitucional, 1(114). Recuperado de http://babel. banrepcultural.org/cdm/compoundobject/collection/ p17054coll26/id/3850/show/3743/rec/8 
República de Colombia. Congreso de la República. (12 de julio de 2012). Código General del Proceso. [Ley 1564]. DO: 48.489 .

República de Colombia. Corte Constitucional. (15 de julio de 2008). Exp. P.E. 030. [Sentencia C-713]. M.P.: Clara Inés Vargas Hernández.

República de Colombia. Corte Constitucional. (8 de octubre de 2002). Exp. D-4437. [Sentencia C-485]. M.P.: Marco Gerardo Monroy Cabra.

República de Colombia. Corte Constitucional. (8 de octubre de 2002). Exp. D-3991. [Sentencia C-830]. M.P.: Jaime Araujo Rentería.

República de Colombia. Corte Constitucional. (18 de noviembre de 1999). Exp. D-2407. [Sentencia C-925]. M.P.: Vladimiro Naranjo Mesa.

Restrepo, C. (2011). El imperio de la discrecionalidad judicial. Criterio Jurídico, 8(1). 195-216.

Ricaurte, S. (2011). Transformando la cultura jurídica en Colombia; una propuesta para superar las resistencias y desafíos en la implementación de la oralidad en el proceso civil. Revistas ICDP, 37(1). http://dx.doi. org/10.32853/01232479.v37.n37.2011.397

Rico, L. (2013). Teoría general del proceso. (3 Ed.). Bogotá, D.C.: Leyer.

Taruffo, M. (2003). Algunos comentarios sobre la valoración de la prueba. Discusiones. (3). 81-97.

Vargas, I. (2007). Roles y desafíos del juez frente a los derechos fundamentales. X encuentro de la jurisdicción ordinaria. Cali, Colombia.

Villamil, E. (2012). Algunos apuntes acerca de las cautelas en el Código General del Proceso. XXXIII Congreso colombiano de derecho procesal. Universidad Libre, Cartagena, Colombia.

Zagrebelsky, G. (2007). El derecho dúctil. (7 Ed.). Torino: Trotta. 
El presente artículo de investigación hace parte del proyecto de investigación titulado: "Constitucionalismo global, derechos fundamentales y región caribe", financiado por la Corporación Universitaria del Caribe, CECAR. Adscrito a su Facultad de Derecho y Ciencias Políticas, y al Grupo de Investigación GISCER, vinculado a la línea de investigación sobre Derechos Humanos.

Yezid Carrillo de la Rosa es Abogado de la Universidad Nacional (Colombia) y Especialista en Derecho Público de la Universidad Externado (Colombia). Especialista en Ética y Filosofia Política de la Universidad de Cartagena (Colombia). Magister en Derecho de la Universidad Nacional. Doctor en Derecho de la Universidad Externado. Decano de la Facultad de Derecho y Ciencias Políticas de la Universidad de Cartagena. Profesor Titular de Filosofia del Derecho y Argumentación Jurídica, de la Universidad de Cartagena y la Universidad Libre de Cartagena (Colombia). https://orcid.org/00000001-5362-3752

Abraham Zamir Bechara Llanos es Abogado suma cum laude y Especialista en Derecho Constitucional de la Universidad Libre (Colombia). Magister magna cum laude de la Universidad del Norte (Colombia). Doctor en Derecho de la Universidad Autónoma de Barcelona (España). Profesor Investigador TC, de la Facultad de Derecho y Ciencias Políticas de la Corporación Universitaria del Caribe-CECAR (Colombia) y Mienbro del Grupo de Investigación GISCER. Profesor Asociado de las asignaturas de Hermenéutica y Argumentación Legal y Filosofia del Derecho en la misma entidad. https://orcid.org/0000-0002-6571-9804 